\title{
Generation and characterization of the human neutralizing antibody fragment Fab091 against rabies virus
}

\author{
Chen $\mathrm{LI}^{1,3,4}$, Feng ZHANG ${ }^{1,3}$, Hong $\mathrm{LIN}^{1}$, Zhong-can WANG ${ }^{2}$, Xin-jian LIU ${ }^{1}$, Zhen-qing FENG ${ }^{1,3}$, Jin ZHU ${ }^{1,2, *}$, \\ Xiao-hong GUAN $^{1, *}$ \\ ${ }^{1}$ Key Laboratory of Antibody Technique of Ministry of Health, Nanjing Medical University, Nanjing 210029, China; ${ }^{2}$ Huadong Medical \\ Institute of Biotechniques, Nanjing 210002, China; ${ }^{3}$ Department of Pathology, Nanjing Medical University, Nanjing 210029, China; \\ ${ }^{4}$ Department of Pathology, the Affiliated Hospital of Xuzhou Medical College, Xuzhou 221002, China
}

Aim: To transform the human anti-rabies virus glycoprotein (anti-RABVG) single-chain variable fragment (scFv) into a Fab fragment and to analyze its immunological activity.

Methods: The Fab gene was amplified using overlap PCR and inserted into the vector pComb3XSS. The recombinant vector was then transformed into E coli Top10F' for expression and purification. The purified Fab was characterized using SDS-PAGE, Western blotting, indirect ELISA, competitive ELISA, and the fluorescent antibody virus neutralization test (FAVN), respectively, and examined in a Kunming mouse challenge model in vivo.

Results: A recombinant vector was constructed. The Fab was expressed in soluble form in E coli Top10F'. Specific binding of the Fab to rabies virus was confirmed by indirect ELISA and immunoprecipitation (IP). The neutralizing antibody titer of Fab was 10.26 IU/mL. The mouse group treated with both vaccine and human rabies immunoglobulin (HRIG)/Fab091 (32 IU/kg) showed protection against rabies, compared with the control group $(P<0.05$, Logrank test).

Conclusion: The antibody fragment Fab was shown to be a neutralizing antibody against RABVG. It can be used together with other monoclonal antibodies for post-exposure prophylaxis of rabies virus in future studies.

Keywords: rabies; Fab engineered antibody; neutralizing antibodies

Acta Pharmacologica Sinica (2011) 32: 329-337; doi: 10.1038/aps.2010.209; published online 31 Jan 2011

\section{Introduction}

Rabies is one of the most fatal central nervous system diseases and is a threat to humans and other mammals. The rabies virus (RABV) belongs to the Rhabdoviridae family and constitutes the prototype of the lyssa viruses ${ }^{[1]}$. Rabies kills more than 50000 people and millions of animals worldwide every year $^{[2]}$. The progress of infection is rapid, and the mortality rate is nearly $100 \%$. The glycoprotein of the rabies virus (RABVG) has been studied extensively for many years. It is a crucial protein for determining the neurovirulent nature of the rabies virus and is an important antigen for inducing protective immunity ${ }^{[3]}$. Among the different antibodies elicited after immunization, neutralizing antibodies specific to the RABVG are thought to provide protection ${ }^{[4]}$. We screened out a human

\footnotetext{
${ }^{*}$ To whom correspondence should be addressed.

E-mail zjsimmons@yahoo.com.cn (Jin ZHU); xhguan@163.com (Xiao-hong GUAN)

Received 2010-05-31 Accepted 2010-11-14
}

anti-RABVG single-chain variable fragment $(\mathrm{scFv})$ from an immune phage antibody library ${ }^{[5]}$. Based on the discrepancies between the native conformations of $\mathrm{scFv}$ and $\mathrm{IgG}$, if the $\mathrm{scFv}$ was shown to be a neutralizing antibody, we would not consider the IgG, for scFv having the same neutralizing activity. In addition, the small molecular weight, short half-life, and expression type of the inclusion body also restrained the therapeutic application of the $\mathrm{scFv}^{[6]}$.

In the present study, the $\mathrm{scFv}_{\mathrm{V}}$ was transformed into a Fab fragment with a larger molecular weight and longer half-life. Fab has the same native conformation as IgG. Accordingly, exploration of the immunological activity of Fab will be helpful in preparing the human IgG. In this study, we transformed the human anti-RABVG scFv into a Fab fragment and to analyze its immunological activity.

\section{Materials and methods}

The rabies virus strain CTN was provided by the Wuhan 
Institute of Biologic Products, Wuhan, China. The rabies virus strains (CVS-11 and CVS-24) and BHK-21 cells were obtained from the Veterinary Institute of the Academy of Military Medical Sciences, Changchun, China. The XL1-Blue and Top10F' Escherichia coli strains were obtained from the Medical Research Council, Lab of Molecular Biology, University of Cambridge, Cambridge, UK. The plasmids pComb3XSS and pComb3X $\lambda$ were obtained from the Barbas Laboratory, TSRI, La Jolla, CA, USA. The horseradish peroxidase-conjugated goat anti-human IgG (Fab specific) was obtained from Sigma, St Louis, MO, USA. The competitive ELISA kit (20080526) was purchased from the Veterinary Institute of the Academy of Military Medical Sciences, Changchun, China. The Kunming mice were provided by the Medical College of Jilin University, Changchun, China. In addition, all the in vivo experiments were approved by the Ethics Committee on Laboratory Animals of Nanjing Medical University.

\section{Construction of human anti-RABV antibody Fab fragment}

The human $V_{H}$ and $V_{L}$ genes were amplified from the antiRABVG scFv plasmid by PCR. The forward primer of $\mathrm{V}_{\mathrm{H}}$ was $\mathrm{V}_{\mathrm{H}} \mathrm{F}$ : 5'-GCTGCCCAACCAGCCATGGCCCAGGTGCAGCTGGTGCAGTCTGG-3' ${ }^{\prime}$, which contained 21 complementary bases to the reverse primer of human IgG1 $C_{L}$ (italicized). The reverse primer of $\mathrm{V}_{\mathrm{H}}$ was $\mathrm{V}_{\mathrm{H}} \mathrm{R}$ : 5'-CGATGGGCCCTTGGTGGAGGCTGAGGAGACGGTGACCAGGGTTCC-3', which contained 21 complementary bases to the forward primer of human IgG1 $\mathrm{C}_{\mathrm{H}} 1$ (italicized) for overlap PCR. The $\mathrm{V}_{\mathrm{L}}$ gene was amplified using the forward primer $\mathrm{V}_{\mathrm{L}} \mathrm{F}$ : 5'-GGGCCCAGGCGGCCCAGTCTGCCCTGACTCAGCCTCGCTCAGTGTCCGGG-3', which contained the restriction endonuclease $S f i$ I site (underlined), and the reverse primer $\mathrm{V}_{\mathrm{L}} \mathrm{R}$ : $5^{\prime}$-CGAGGGGGCAGCCTTGGGCTGACCTAGGACGGTCAGCTTGGTCCCTCCGCCGAAAACCAC-3', which contained 21 complementary bases to the forward primer of human IgG1 $C_{L}$ (italicized) for overlap PCR. The human IgG constant domains $\mathrm{C}_{\mathrm{H}} 1$ and $\mathrm{C}_{\mathrm{L}}$ were amplified from a recombinant vector pComb3X $\lambda$. The PCR conditions were repeated for 25 cycles at $94^{\circ} \mathrm{C}$ for $30 \mathrm{~s}, 60^{\circ} \mathrm{C}$ for $30 \mathrm{~s}$, and $72^{\circ} \mathrm{C}$ for $1 \mathrm{~min}$, followed by a final extension time of $10 \mathrm{~min}$ at $72^{\circ} \mathrm{C}$. The genes of $\mathrm{C}_{\mathrm{H}} 1$ (human IgG1) and $\mathrm{V}_{\mathrm{H}}$ were used as templates for generation of the Fd fragment by overlap PCR with a pair of primers - FdF: 5'-GCTGCCCAACCAGCCATGGCCCTCGAGGTGAAGCTGGTGGAGTC-3' and FdR: 5' -AGAAGCGTAGTCCGGAACGTC-3'. The assembly of $\mathrm{V}_{\mathrm{H}}$ and $\mathrm{C}_{\mathrm{H}} 1$ was performed by PCR for 15 cycles of $94^{\circ} \mathrm{C}$ for $15 \mathrm{~s}, 56^{\circ} \mathrm{C}$ for $15 \mathrm{~s}$, and $72^{\circ} \mathrm{C}$ for $2 \mathrm{~min}$, followed by a final extension time of $10 \mathrm{~min}$ at $72^{\circ} \mathrm{C}$. Similarly, human $C_{L}$ and $V_{L}$ fragments were joined to generate the light chain with the pair of primers LF: $5^{\prime}$-GGGCCCAGGCGGCCGAGCTCGACATTGTGATGCACAGTC-3' and LR: 5'-GGCCATGGCTGGTTGGGCAGC-3'. In the third round of $\mathrm{PCR}$, the $\mathrm{Fd}$ and $\mathrm{L}$ chains were mixed in equal parts to generate the overlap full-length Fab products. The conditions for PCR was 6 cycles without primers at $94^{\circ} \mathrm{C}$ for $50 \mathrm{~s}, 56^{\circ} \mathrm{C}$ for $30 \mathrm{~s}, 72^{\circ} \mathrm{C}$ for $3 \mathrm{~min}$, and then 20 cycles with a pair of human primers - FabF: 5'-GGGCCCAGGCGGCCGAGCTCGACATTGTGATGACACAGTC-3' and FabR: 5' CGGAACGTC-3' ${ }^{\prime 7]}$.

\section{Construction of recombinant plasmid}

A phagemid pComb3XSS was used for expression of the Fab fragment $t^{[8]}$. The vector pComb3XSS and the Fab fragments were digested by the restriction endonuclease $S f i$ I (New England Biolabs, Ipswich, MA, USA) ${ }^{[9,10]}$ and ligated to create recombinants. The recombinants were transformed into competent $E$ coli XL1-Blue cells by standard chemical methods $\left(\mathrm{CaCl}_{2} / \text { heat shock }\right)^{[11]}$. After overnight incubation, the clones were checked for the presence of the insert by colony PCR and DNA sequencing.

\section{Expression and purification of Fab fragment}

The recombinant phagemid, which was confirmed to contain the correct sequence by DNA sequencing, was transformed into $E$ coli Top $10 \mathrm{~F}^{\prime}$ for expression by way of soluble protein expression ${ }^{[12]}$. The cells were harvested by centrifugation, and the cell pellet was suspended in PBS. The periplasmic extract was obtained by sonication and centrifugation of the suspended products. Twenty microliters of the samples were used for denaturing polyacrylamide gel analysis. The gels were analyzed by staining with Coomassie blue and Western blotting. The Fab fragment was purified from the supernatant $(150 \mathrm{~mL})$ by affinity chromatography using a HisTrap HP column (1 mL, GE Healthcare, Piscataway, NJ, USA) with a flow rate of $1 \mathrm{~mL} / \mathrm{min}$. The binding buffer was $20 \mathrm{mmol} / \mathrm{L}$ of phosphate buffer ( $\mathrm{pH} 7.4$ ) with $20 \mathrm{mmol} / \mathrm{L}$ imidazole and 500 $\mathrm{mmol} / \mathrm{L} \mathrm{NaCl}$. The Fab was eluted using $20 \mathrm{mmol} / \mathrm{L}$ phosphate buffer ( $\mathrm{pH} 7.4$ ) with imidazole at different concentrations $(50,100,200,300,400$, and $500 \mathrm{mmol} / \mathrm{L})$. The eluted Fab fractions were concentrated using an Amicon Ultra centrifugal filter device (10 kDa cut-off, Millipore, Bedford, MA, USA) and dissolved in PBS. The purified Fab fragment was named Fab091.

\section{SDS-PAGE and Western blot analysis}

The purified Fab091 fragment was resolved by 12\% SDSPAGE under reducing conditions with $\beta$-mercaptoethanol $(\beta-\mathrm{ME})$. For Western blot analysis, Fab091 was detected by HRP-conjugated goat anti-human IgG (1:2000), and the blot was developed using the $\mathrm{DAB} / \mathrm{H}_{2} \mathrm{O}_{2}$ system.

\section{Antigen binding assays for Fab091 Indirect ELISA}

A 96-well microplate (Costar, Washington, DC, USA) was coated with $2 \mu \mathrm{g} / \mathrm{mL}$ of rabies virus strain CTN. The Fab091 fragment $(0.2 \mathrm{mg} / \mathrm{mL})$ and $E$ coli-negative supernatant was added to antigen-coated wells in serial two-fold dilutions (1:5, 1:10, 1:20, 1:40, 1:80, 1:160, 1:320, and 1:640), and bound antibodies were detected by HRP-conjugated goat anti-human IgG (1:5000). Each sample had two duplicate wells. PBS was used as a blank control, and its $\mathrm{OD}_{450}$ value was assigned as 0 . 


\section{Competitive ELISA (C-ELISA) of Fab091 and scFv}

Fab091 (0.5 mg/mL) was added into a 96-well microplate plate coated with RABV. Then the original anti-RABVG ScFv was added at dilution ratios of 1:1, 1:5, 1:25, and 1:125 and incubated in these wells for $1 \mathrm{~h}$ at room temperature. After washing five times with PBST (20 mmol/L PBS, 0.05\% Tween 20), HRP-conjugated mouse anti-human IgG (Fab specific) was added to the wells and incubated for $1 \mathrm{~h}$ at room temperature. An anti-Met $\mathrm{scFv}$ antibody ${ }^{[13]}$ was used as a negative control in lieu of anti-RABVG scFv, and the blank control lacked scFv. The final results were expressed as percentages of inhibition (PI). The PI values for the Fab091 were calculated with the following formula:

$$
\mathrm{PI}=1-\left(O D_{\mathrm{b}}-O D_{\mathrm{s}}\right) / O D_{\mathrm{b}} \times 100 \%
$$

(s: sample, b: blank control)

A competitive ELISA kit was used to detect the neutralizing titer of Fab091. For the ELISA, the standard serum was obtained from volunteers who had been inoculated with rabies vaccine. The titers of neutralizing antibodies in the serum were detected by the FAVN method, and the serum was diluted to $0.25,0.5,1.0,2.0,4.0$, and $8.0 \mathrm{IU} / \mathrm{mL}$. The neutralizing antibodies in the ELISA were murine monoclonal antibodies against RABVG conjugated with horseradish peroxidase. One hundred microliters of HRP-conjugated antibodies against RABVG were mixed with $100 \mu \mathrm{L}$ of different titers of standard serum $(0.25,0.5,1.0,2.0,4.0$, and $8.0 \mathrm{IU} / \mathrm{mL})$ and added to a RABVG-coated ELISA microplate. Meanwhile, 100 $\mu \mathrm{L}$ of HRP-conjugated antibodies and $100 \mu \mathrm{L}$ of Fab091 were mixed in the coated microplate. Every sample had two duplicate wells. Following incubation for $45 \mathrm{~min}$ at $37^{\circ} \mathrm{C}$, the plates were washed, and a tetramethylbenzidine (TMB) substrate solution was added. After incubation for $15 \mathrm{~min}$ at $37^{\circ} \mathrm{C}$, the reaction was stopped by adding $2.0 \mathrm{~mol} / \mathrm{L}$ sulfuric acid, and the $O D_{450}$ was measured by a Multiskan Spectrum Microplate Photometer. The neutralizing antibody titer of Fab091 was calculated according to the $O D_{450}$ values and the titers of the standard samples ${ }^{[14,15]}$.

\section{Immunoprecipitation (IP) and mass spectrometry (MS)}

A mixture of $20 \mu \mathrm{L}$ of Fab091 and $40 \mu \mathrm{L}$ of CTN was resuspended in $1 \mathrm{~mL}$ of PBS and incubated for $1 \mathrm{~h}$ at $4{ }^{\circ} \mathrm{C}$. Protein $\mathrm{G}$ magnetic beads $(30 \mu \mathrm{L})$ were added to the mixture for immunoprecipitation (IP). The mixture was whirled gently and incubated with agitation at $4{ }^{\circ} \mathrm{C}$ for $12 \mathrm{~h}$. The beads were collected by centrifugation at $4000 \times g$ for $5 \mathrm{~min}$ and then washed three times with PBS. The supernatant was removed. Finally, the beads were resuspended with loading buffer and boiled, and the proteins were resolved by 12\% SDS-PAGE. The resolved proteins were transferred onto a nitrocellulose membrane and detected by Rab-50 (sc-57994, Santa Cruz, CA, USA), which is a mouse monoclonal anti-RABVG antibody. After blocking in 5\% milk in PBST for $30 \mathrm{~min}$ and washing three times with PBST, the membrane was incubated with the HRP-conjugated goat anti-mouse IgG (Sigma, St Louis, MO, USA). Finally, the blot was developed using the DAB $/ \mathrm{H}_{2} \mathrm{O}_{2}$ system. The band that corresponded to the blot $(67 \mathrm{kDa})$ on a separate polyacrylamide gel stained with Coomassie blue was analyzed by mass spectrometry (MS). Detected spots were excised from the gels, which were stained with Coomassie Brilliant blue. The gel chips were excised and destained with a solution containing $100 \mathrm{mmol} / \mathrm{L} \mathrm{NH}_{4} \mathrm{HCO}_{3}$ and $50 \%$ ethane nitrile ( $\mathrm{pH}$ 8.0). After hydrating with ethane nitrile and drying, the gel chips were hydrated in a minimal volume of trypsin (Promega Corporation, Madison, WI, USA) solution and incubated at $37^{\circ} \mathrm{C}$ overnight. The gel pieces were extracted with $50 \%$ acetonitrile/2.5\% trifluoroacetic acid at $37{ }^{\circ} \mathrm{C}$ for one hour with sonication, and the supernatant was removed. The extraction was repeated twice. A gel slice was dissolved in $0.1 \%$ trifluoroacetic acid (Sigma, St Louis, MO, USA), desalted, and concentrated using ZipTips (Millipore, Bedford, MA, USA). The peptide solution $(0.5 \mu \mathrm{L})$ was mixed with $0.5 \mu \mathrm{L}$ of matrix ( $5 \mathrm{mg} / \mathrm{mL}$ a-cyano-4-hydroxycinnamic acid in $30 \%$ acetonitrile/ $0.1 \%$ TFA), spotted on a target disk, and allowed to air-dry. Samples were analyzed by MS (Bruker Daltonics, Leipzig, Germany). Protein database searching was performed with the MASCOT search engine (http://www. matrix science.com; Matrix Science, UK) ${ }^{[16]}$.

\section{Affinity analysis by surface plasmon resonance (SPR)}

SPR was performed on a BIAcore T100 (GE, Piscataway, NJ, USA) analytical system. RABV was diluted to $5 \mu \mathrm{g} / \mathrm{mL}$ with acetate buffer $(10 \mathrm{mmol} / \mathrm{L}$ sodium acetate, $\mathrm{pH}$ 5.5, GE, Piscataway, NJ, USA) and immobilized on the surface of a CM5 sensor chip (GE, Piscataway, NJ, USA) to capture purified Fab091. Fab091 was diluted by HBS-EP buffer (GE, USA) at concentrations ranging from 31.25 to $1000 \mathrm{nmol} / \mathrm{L}$ and performed at a constant flow rate of $30 \mu \mathrm{L} / \mathrm{min}$ for $3 \mathrm{~min}$ at $25^{\circ} \mathrm{C}$. The association time was $180 \mathrm{~s}$, and the dissociation time was $600 \mathrm{~s}$. The constants for association $\left(\mathrm{k}_{\mathrm{a}}\right)$ and dissociation rate $\left(\mathrm{k}_{\mathrm{d}}\right)$ and the equilibrium constant for dissociation $\left(K_{D}, K_{D}=k_{d} / k_{a}\right)$ were obtained using global fittings from the Langmuir binding model (1:1 binding model). The sensor grams were evaluated using the BIAcore T100 evaluation software (GE, Piscataway, NJ, USA).

\section{Detection of Fab091 neutralizing activity}

To perform the FAVN test, BHK-21 cells and the RABV strain CVS-11 were used. The positive control serum against RABV was obtained from adult dogs vaccinated with rabies vaccine. The neutralizing antibody titers were determined by the Weybridge Laboratory (UK), a rabies reference laboratory of OIE, the World Organization for Animal Health. The serum was then diluted to $0.5 \mathrm{IU} / \mathrm{mL}$ and used as a standard serum. Serial three-fold dilutions of the positive and negative control sera and the Fab091 were made in 100- $\mu \mathrm{L}$ volumes in microplate wells. Each sample was added to four adjacent wells and serially diluted five times using a multichannel pipette. Fifty-microliter challenge virus suspensions containing $100 \mathrm{TCID}_{50}$ were added to each well. The microplates were incubated for one hour at $37^{\circ} \mathrm{C}$ in a humidified incubator with $5 \% \mathrm{CO}_{2}$. Following incubation, $2 \times 10^{4} \mathrm{BHK}-21$ cells in 50 $\mu \mathrm{L}$ of culture medium were added to each well, and the plates 
were incubated for another $48 \mathrm{~h}$. Thereafter, the medium was discarded, and the plates were rinsed in PBS ( $\mathrm{pH} 7.2$ ) and in acetone ( $80 \%$ in distilled water). The plates were then fixed in $80 \%$ acetone for $30 \mathrm{~min}$ at room temperature and air-dried. The staining was carried out by adding $50 \mu \mathrm{L}$ of fluoresceinisothiocyanate-conjugated anti-rabies serum. After incubation for $30 \mathrm{~min}$ at $37^{\circ} \mathrm{C}$, the plates were washed twice with PBS. The FAVN result was assessed with a fluorescence microscope (image A.l; Zeiss, Germany). The total area of each well was examined. The well was considered positive if one or more fluorescent cells were observed; otherwise, it was considered negative. The $50 \%$ endpoint of the antibody $\left(D_{50}\right)$ content of the test sample and virus titers $\left(\mathrm{TCID}_{50}\right)$ were calculated according to the Spearman-Karber method ${ }^{[17]}$. The neutralizing titer of Fab091 was calculated based on the number of negative wells and their dilutions, compared with those of the standard serum included in the test ${ }^{[18]}$.

\section{Animals and inoculation}

A lethal animal model mimicking rabies exposure was used as described elsewhere ${ }^{[19-21]}$. The mice were treated as described in Table 1. Four-week-old pathogen-free Kunming mice (10-12 g, 8 mice/group, 9 groups) were infected with 100 $\mathrm{LD}_{50} / 0.05 \mathrm{~mL} \mathrm{CVS-24}$ on $\mathrm{d} 0$ and $\mathrm{d} 7$. The mice were inoculated in the hind limb with rabies vaccine (Sanofi-PASTEUR $\mathrm{SA}$, France). In addition, human rabies immunoglobulin (HRIG, Taibang Health, Taian, China) at $20 \mathrm{IU} / \mathrm{kg}$ and Fab091 (treated with $32,20,8,2$, and $0.5 \mathrm{IU} / \mathrm{kg}$ ) were administered on $\mathrm{d} 0$. The mice were evaluated for $28 \mathrm{~d}$ for clinical signs of neurology and death. In the control group, the mice were injected with $100 \mathrm{LD}_{50} / 0.05 \mathrm{~mL}$ of the CVS-24 strain. The experiments using the CVS-24 strain were performed in a Biosafety Level 3 Laboratory (BSL-3) ${ }^{[22]}$.

Table 1. Rabies virus postexposure prophylactic trial.

$\mathrm{HRIG+}$

\begin{tabular}{lccccccccc} 
Treatment & Vacc & \multicolumn{4}{c}{ Fab091+vacc } & \multicolumn{4}{c}{ Fab091 vacc PBS } \\
dose & A & B & C & D & E & F & G & H & I \\
(IU/kg) & 0 & 0.5 & 2 & 8 & 20 & 32 & 20 & 20 & 0 \\
& & & & & & & & & \\
Virus & + & + & + & + & + & + & + & + & + \\
Vaccine & + & + & + & + & + & + & - & + & - \\
Fab091 & - & + & + & + & + & + & + & - & - \\
HRIG & - & - & - & - & - & - & - & + & - \\
PBS & - & - & - & - & - & - & - & - & +
\end{tabular}

+, disposed; -, undisposed; HRIG, human rabies immunoglobulin; PBS, phosphate-buffered saline.

\section{Statistical analysis}

Kaplan-meier method was used for survival analysis of Kunming mice after rabies virus challenge. Statistical analyses were performed with SPSS 11.5 statistical software package (SPSS Inc, Chicago, IL, USA). A $P$ value $<0.05$ was accepted as statistically significant.

\section{Results}

Amplification of the human anti-RABV antibody Fab gene fragment and construction of the expression vector

The human anti-RABV antibody Fab gene fragment was amplified in three rounds of PCR, as described in Materials and methods. The cloning strategy is shown in Figure 1.
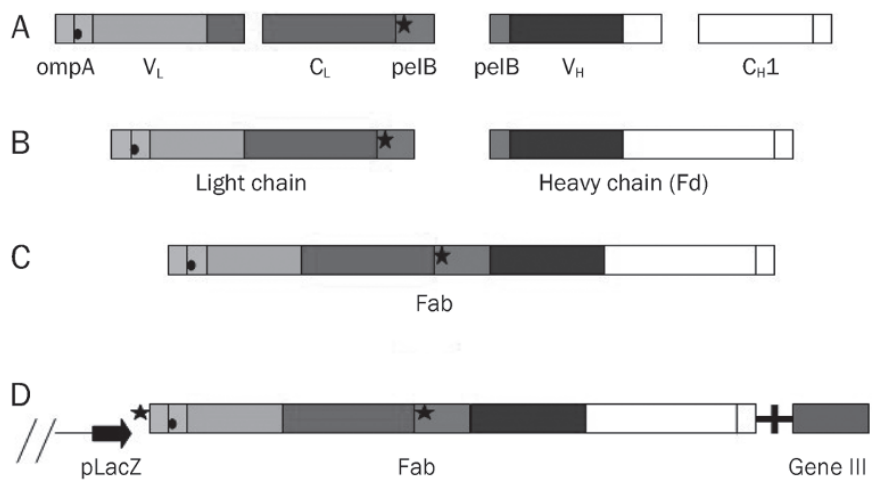

Figure 1. Construction of plasmid pComb3XSS-Fab for the production of Fab antibody fragments in E coli. Genes of light-chain and heavy-chain Fd fragments were fused by overlap-extension PCR, and cloned directionally by using two asymmetric sites of the rare cutter Sfi I. Fab was transcribed as a single transcript under the control of one LacZ promoter. The amber stop codon (cross) between the antibody genes and bacteriophage gene III enables the production of soluble Fab fragments in a non suppressor strain of $E$ coli. (A) The genes for the variable and constant regions were amplified separately. (B) Heavy-chain Fd and light chain DNA were assembled by variable regions and their constant counterpart respectively by using overlap PCR. (C) Fd and light chain were fused to form Fab-encoding sequences by overlap PCR. Fab genes were directionally cloned into pComb3XSS phagemid by using the Sfi I site. (D) Both L chain fragment and Fd fragment were transported to the periplasm of $E$ coli.

\section{Purification and detection of soluble Fab fragment}

Purified Fab091 was resolved by 12\% SDS-PAGE under reducing conditions. Both the $\mathrm{Fd}(34 \mathrm{kDa})$ and $\mathrm{L}$ chains (26 $\mathrm{kDa}$ ) were detected in the monomeric form (Figure 2A). The expression of Fab091 was confirmed using Western blotting (Figure 2B).

\section{Specific binding of Fab091 fragment to RABV}

Binding of the Fab091 fragment to RABV was detected by indirect ELISA as shown in Figure 3. The $O D_{450}$ values showed a gradient change that was accompanied by a decreasing concentration of Fab091.

In the competitive ELISA, as shown in Figure 4A, the PI of Fab091 ranged from $73.65 \%$ to $11.83 \%$ concomitant with the decreasing concentration of scFv. Less than $10 \%$ inhibition was observed for the anti-Met $\mathrm{scFv}$ negative control.

A standard curve for the competitive ELISA is shown in Figure $4 \mathrm{~B}$. The range of the standard curve was 0 to $8 \mathrm{IU} / \mathrm{mL}$. If the $O D_{450}$ value was between 0 to $8 \mathrm{IU} / \mathrm{mL}$, the neutralizing antibody titers could be read from the curve. In Figure $4 \mathrm{~B}$, the titers of standard serum decreased with increasing $O D_{450}$ val- 


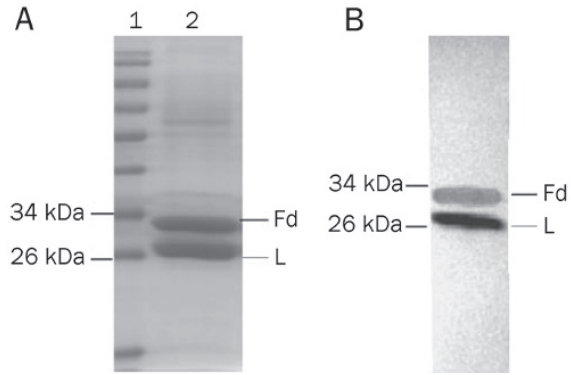

Figure 2. SDS-PAGE and Western blot of the purified Fab091 fragment after purification. The purified Fab091 was resolved in 12\% SDS-PAGE under reducing conditions and stained with Coomassie blue. The heterodimer was dissociated into light chain (26 kDa) and Fd (34 kDa). (A) Lane 1: protein marker (\#0671, Fermantas, Burlington, Ontario, Canada); Lane 2: the purified Fab091 fragment. (B) Electrobloted Fab091 fragments were detected by goat anti-human IgG-HRP conjugate (1:2000 dilution).

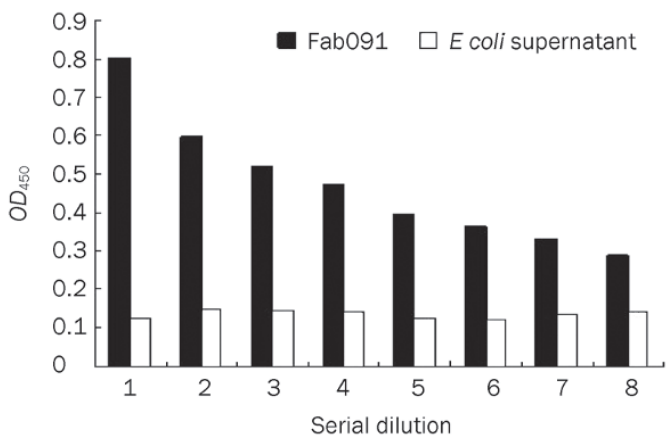

Figure 3. Indirect ELISA of the different dilutions of Fab091 fragment. The ELISA plate was coated with rabies virus strain CTN at $2 \mu \mathrm{g} / \mathrm{mL}$. (1-8): The virus reacted with Fab091 which was in serial two-fold dilution (1:5, 1:10, 1:20, 1:40, 1:80, 1:160, 1:320, and 1:640) and incubated for $2 \mathrm{~h}$ at room temperature. $E$ coli Top10F' supernatant was used as control. The plate was washed five times with PBST, followed by incubation with goat anti-human IgG HRP-conjugated (1:5000).

ues. The $O D_{450}$ of the test sample was 1.022 , so the result was negative.

IP was also used for the detection of the specific binding of Fab to the rabies virus strain CTN (Figure 5A). Four peptide sequences (Table 2) matched with RABVG by MS analysis (Figure 5B) were found when the identified peptides were compared with the known sequences of RABVG in the SWISS PROT database. Mass tolerance was allowed within $0.05 \%$.

Table 2. Amino-acid residue sequences of matched peptides.

\begin{tabular}{lrl}
\hline & Relative intensity & \multicolumn{1}{c}{ Amino-acid residue } \\
\hline 1 & 983.431 & TCGFVDER \\
2 & 1070.575 & STQHGLGGTGR \\
3 & 2118.972 & YEESLHNPYPDYHWLR \\
4 & 2708.251 & YVLMSAGVLIALMLTIFLMTCCR \\
\hline
\end{tabular}

A

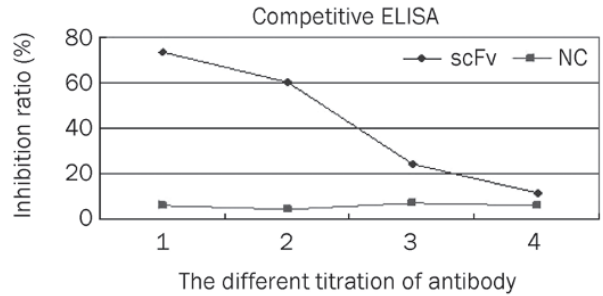

B

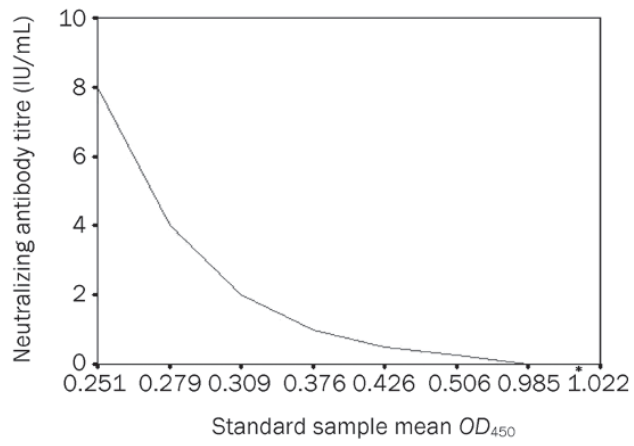

Figure 4. Competitive ELISA detection. (A) The rabies virus strain CTN was used as coated antigen for Competitive ELISA of scFv and Fab091. (1-4): The scFv was diluted to 1:1, 1:5, 1:25, 1:125, and incubated with Fab091. PI of Fab091 ranged from $73.65 \%$ to $11.83 \%$ (73.65\%, 60\%, $24.95 \%$, and $11.83 \%$ ) with decreasing concentration of scFv. Less than $10 \%$ inhibition was observed for negative anti-Met ScFv. (B) Standard curve for Competitive ELISA: The 96-well microplate was coated with RABVG. HRP-conjugated antibodies against RABVG were mixed with different titers of standard serum $(0.25,0.5,1.0,2.0,4.0$, and $8.0 \mathrm{IU} / \mathrm{mL})$. Meanwhile, HRP-conjugated antibodies and Fab091 were mixed in the coated microplate and incubated. The mean $O D_{450}$ value of Fab091 well was 1.022, according to the standard curve ranging from 0 to $8 \mathrm{IU} / \mathrm{mL}$, so the corresponding titre was 0 .

Protein matching with a MASCOT score of $>69$ was considered statistically significant $(P<0.05)$.

\section{Affinity assay of Fab091}

The binding affinities between rabies protein and purified Fab091 were analyzed by Biacore T100 (GE, Piscataway, NJ, USA). Fab091 had a high affinity with a $K_{\mathrm{D}}$ of $6.268 \mathrm{E}-10 \mathrm{M}$. $\left(x^{2}=1.09, U=5\right)$. The interaction between Fab091 and rabies virus is shown in Figure 6.

\section{Neutralizing activity of Fab091}

In the FAVN, no fluorescence was seen in the wells until the standard serum was diluted nine times. There were still two negative wells when the serum concentration was at 1:27 dilution. For the test sample Fab091, no fluorescence was seen until the wells were diluted to 1:81 $(12 \mu \mathrm{g} / \mathrm{mL})$. There was only one negative well at 1:243 dilution. According to the dilution rates and the total number of negative wells, compared with the standard serum $(0.5 \mathrm{IU} / \mathrm{mL})$, the neutralizing antibody titer of Fab091 was calculated to be $10.26 \mathrm{IU} / \mathrm{mL}$.

\section{Activity identification in vivo}

The number of deaths observed in Kunming mice after infec- 
A

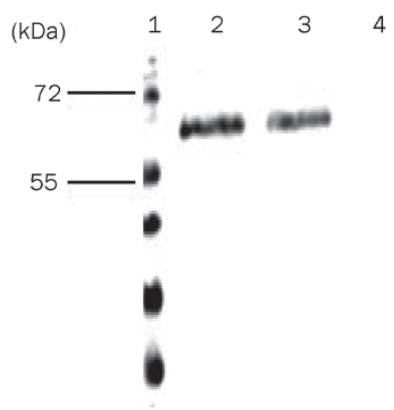

B

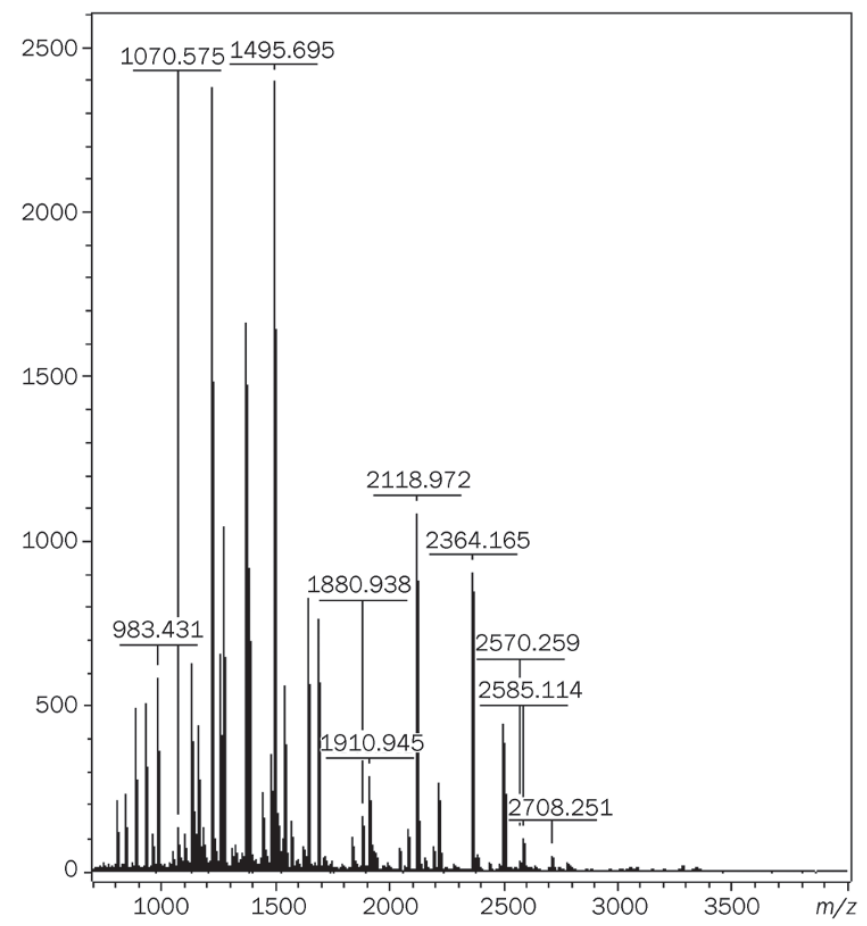

Figure 5. IP and MS analysis of RABVG. (A) Proteins immunoprecipitated by Fab091 were separated by SDS-PAGE and probed with RAB-50 by Western blot. (1): Protein marker; (2-3): One protein was recognized by RAB-50. The molecular weight of the protein was about $67 \mathrm{kDa}$. (4): BHK-21 lysate was used as the negative control to replace Fab091 in the IP. (B) The corresponding $67 \mathrm{kDa}$ band on the polyacrylamide gel was analyzed by mass spectrometry, which was identified as RABVG. MS spectrums of fragment ions were from the $67 \mathrm{kDa}$ protein. Four major $(\mathrm{m} / \mathrm{z}=983.431,1070.575$, 2118.972, 2708.251) ions were detected.

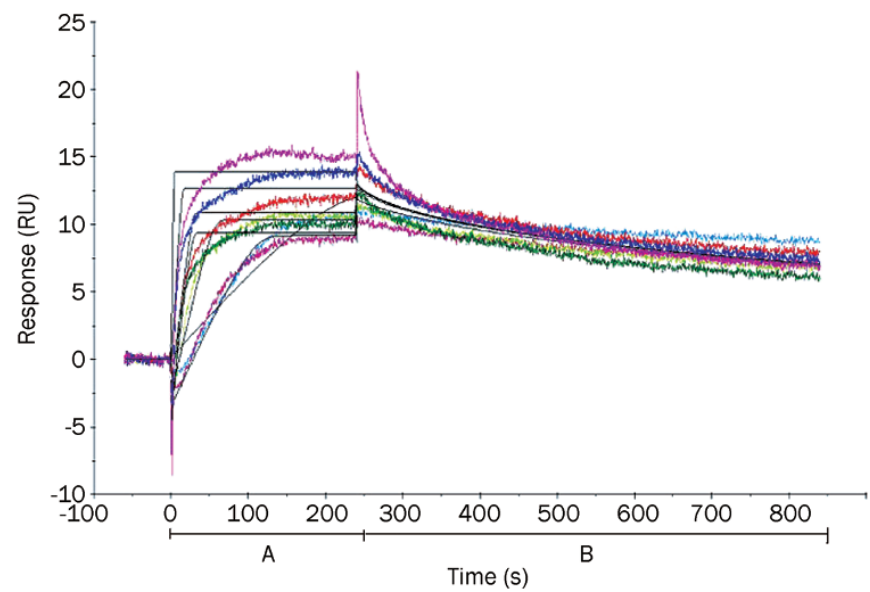

Figure 6. SPR analysis of Fab091 and rabies virus interaction. Fab091 (1 $\mathrm{mg} / \mathrm{mL}$ ) was subjected to SPR analysis. CM5 sensor chip was activated by the injection of 1-ethyl-3-(3-dimethylaminopropyl)-carbodiimide hydrochloride (EDC)/N-hydroxysuccinimide (NHS). Rabies virus was coated on the CM5 chip, and the surface was washed with $10 \mathrm{mmol} / \mathrm{L}$ HEPES ( $\mathrm{pH}$ 7.4) for $200 \mathrm{~s}$ and then Fab091 was injected. Dilution rates of Fab091 were 31.25, 62.5, 125, 250, 500, $1000 \mathrm{nmol} / \mathrm{L}\left(C h i^{2}=1.09, \mathrm{U}=5\right.$, $\left.R_{\max }=13.05 \mathrm{RU}\right)$. (A) Association stage; (B) Dissociation stage.

tion with CVS-24 at $28 \mathrm{~d}$ is shown in Table 3 , and a survival curve is shown in Figure 7 for the Kunming mice, according to the Kaplan-Meier method. A survival rate of $12.5 \%(1 / 8)$ was observed in the group with CVS-24 infection. A survival rate of $25 \%(2 / 8)$ was observed in the control group, which

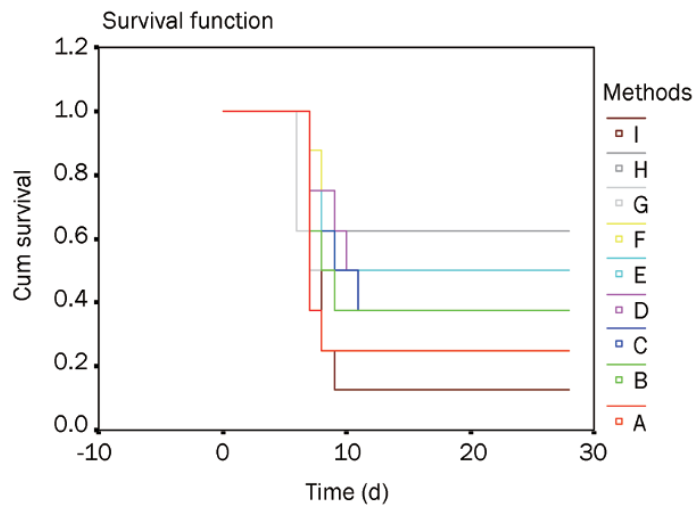

Figure 7. Kaplan-Meier survival curve for Kunming mice after rabies virus challenge. Mice ( $n=8$ per group) were challenged with CVS-24 strain on $\mathrm{d} 0$. Three hours later ( $\mathrm{d} 0$ ), the mice in treatment groups were inoculated with rabies vaccine and treated either with $32,20,8,2,0.5 \mathrm{IU} / \mathrm{kg}$ Fab091 or $20 \mathrm{IU} / \mathrm{kg}$ HRIG. The treatment groups also included $20 \mathrm{IU} / \mathrm{kg}$ Fab91 group. The mice in control groups received only PBS. The mice were evaluated twice daily and were sacrificed when neurological signs appeared. Kaplan-Meier survival curves were shown for $\mathrm{d} 0$ to $\mathrm{d} 28$. (A) Vaccine; (B) Vaccine+0.5 IU/kg Fab091; (C) Vaccine+2 IU/kg Fab091; (D) Vaccine+8 IU/kg Fab091; (E) Vaccine+20 IU/kg Fab091; (F) Vaccine+32 IU/kg Fab091 ( $P<0.05$, Logrank test); G: 20 IU/kg Fab091; H: Vaccine+20 IU/kg HRIG ( $P<0.05$, Logrank test); I: PBS. 
Table 3. Deaths of Kunming mice after infected with CVS-24 in $28 \mathrm{~d}$.

\begin{tabular}{|c|c|c|c|c|c|c|c|c|c|}
\hline \multirow{3}{*}{ Days } & Vaccine & \multicolumn{5}{|c|}{ Fab091+vaccine } & \multirow{2}{*}{$\begin{array}{c}\text { Fab091 } \\
\text { G }\end{array}$} & \multirow{2}{*}{$\begin{array}{c}\mathrm{HRIG}+\mathrm{vaccine} \\
\mathrm{H}\end{array}$} & \multirow{2}{*}{$\begin{array}{c}\text { PBS } \\
1\end{array}$} \\
\hline & A & B & C & $\mathrm{D}$ & $E$ & $\mathrm{~F}$ & & & \\
\hline & 0 & 0.5 & 2 & 8 & 20 & 32 & 20 & 20 & 0 \\
\hline 0 & 0 & 0 & 0 & 0 & 0 & 0 & 0 & 0 & 0 \\
\hline 1 & 0 & 0 & 0 & 0 & 0 & 0 & 0 & 0 & 0 \\
\hline 2 & 0 & 0 & 0 & 0 & 0 & 0 & 0 & 0 & 0 \\
\hline 5 & 0 & 0 & 0 & 0 & 0 & 0 & 0 & 0 & 0 \\
\hline 6 & 0 & 0 & 0 & 0 & 0 & 0 & 3 & 0 & 4 \\
\hline 7 & 5 & 3 & 3 & 2 & 2 & 1 & 1 & 1 & 2 \\
\hline 8 & 1 & 2 & 0 & 0 & 0 & 1 & 0 & 2 & 1 \\
\hline 9 & 0 & 1 & 1 & 1 & 1 & 1 & 1 & 0 & 0 \\
\hline
\end{tabular}

A: vaccine; B-F: vaccine+Fab091 (different dilution rates from 0.5 to 32 IU/kg); G: Fab091; H: vaccine+HRIG (20 IU/kg); I: PBS

received vaccine only. The group treated with vaccine and HRIG had a survival rate of $62.5 \%(5 / 8)$. The survival rates were $50 \%(4 / 8), 50 \%(4 / 8), 37.5 \%(3 / 8), 37.5 \%(3 / 8)$, and $25 \%$ $(2 / 8)$ when the mice were treated with $32,20,8,2$, and 0.5 IU/kg Fab091, respectively, and vaccine. The groups that received vaccine and $32 \mathrm{IU} / \mathrm{kg}$ Fab091 (Figure 7) or vaccine and $20 \mathrm{IU} / \mathrm{kg}$ HRIG (Figure 7) were provided with a level of protection against the rabies virus compared to the PBS group $(P=0.0485$ and $P=0.038$, respectively; Logrank test).

\section{Discussion}

Equine anti-RABV immunoglobulin (ERIG) and human antiRABV immunoglobulin (HRIG) have been used for passive rabies immunotherapy. However, ERIG can lead to allergic reactions and blood diseases, and HRIG is expensive and often in short supply ${ }^{[23-25]}$. Recombinant DNA technology and bacterial expression systems used to obtain active antibodies were very attractive compared to hybridoma technology, and antibody molecules can be further engineered to increase their binding affinity. Smaller antibody fragments (such as Fab and $\mathrm{scFv}$ ) can be effectively used for diagnostic and therapeutic application due to their low immunogenicity and better tissue penetration ${ }^{[26]}$. ScFv fragments are composed of $\mathrm{V}_{\mathrm{H}}$ and $\mathrm{V}_{\mathrm{L}}$ with a connecting peptide link. Fab fragments are more stable due to an additional domain-domain interface resulting from the $\mathrm{C}_{\mathrm{H}} 1-\mathrm{C}_{\mathrm{L}}$ association. This structure resulted in higher affinity of purified antibodies ${ }^{[27-30]}$.

Expression of heterologous proteins in bacterial systems can be influenced by many factors such as codon usage, DNAprotein interactions, regulatory factors for transcription and translation, and culture conditions. In the present study, the amber stop codon (cross) enabled the production of soluble Fab fragments in a non-suppressor strain of $E$ coli. We optimized the expression conditions and found that Fab could be expressed in a soluble form at room temperature $\left(22\right.$ to $\left.25^{\circ} \mathrm{C}\right)$.
If the inducing temperature was 30 or $37^{\circ} \mathrm{C}, \mathrm{Fab}$ was most often expressed in the form of inclusion bodies. In the process of purification, it was found that the amount of purified $\mathrm{Fd}$ fragments was less than that of the light chain. This result was possibly due to the $\mathrm{pH}$ value of the binding or washing buffer used for purification being unsuitable for purification of the Fd fragment. Furthermore, we found that the Fab091 fragment was easily eluted by phosphate buffer with a concentration of $100 \mathrm{mmol} / \mathrm{L}$ imidazole and that the eluted protein had a higher purity. In Figure 3, $O D_{450}$ values showed a gradient change that was accompanied by a decreasing concentration of Fab091, which illustrated the high specificity of Fab091 against the RABV. Furthermore, IP and MS analysis results also demonstrated that Fab091 binds specifically to RABVG. The competitive ELISA indicated that Fab091 and the original scFv shared the same epitope. The neutralizing antibodies in the ELISA kit had different epitopes against RABVG from Fab091.

The most critical property of Fab091 was its neutralizing potency to inhibit the entry of CVS-11 into BHK-21 cells. A sufficient level of antibody to inhibit entry is considered to be $0.5 \mathrm{IU} / \mathrm{mL}$, according to the recommendations of the World Health Organization and the Centers for Disease Control and Prevention ${ }^{[3]]}$. Compared with the reported neutralizing concentrations of FabRV01 and FabRV02, which neutralized the CVS-11 at $146 \mu \mathrm{g} / \mathrm{mL}^{[32]}$, Fab091 was used to neutralize the virus at a concentration of only $12 \mu \mathrm{g} / \mathrm{mL}$. FabRV01, FabRV02, and FabRV03 were isolated from a recombinant immune antibody library, differing from the altered Fab091, which was from $\mathrm{scFv}$. These results may provide insight into the neutralization activity of recombinant antibodies.

Vaccination alone in the in vivo study was not sufficient to protect mice from rabies, whereas the treatment of mice with both vaccine and HRIG (20 IU/ kg)/Fab091 (32 IU/kg) provided better protection against rabies than vaccine alone $(P<0.05$, Logrank test). However, the survival rates of the 
groups treated with vaccine and Fab091 $(32 \mathrm{IU} / \mathrm{kg})$ were lower than that of the vaccine and HRIG (20 IU/ kg)-treated group. This result could be interpreted as follows. First, the in vivo clearance of RABV is a complicated process. Compared with small-molecular-weight antibodies, the IgG antibody (HRIG), with antibody-dependent cellular cytotoxicity and complement-mediated cytotoxicity, has a greater scavenging capacity in $v i v o^{[33,34]}$. The neutralizing activity of Fab is usually less than that of full-length IgG because of the monovalence of the Fab fragments and the lack of Fc fragment on an IgG molecule. Human Fab may exhibit even greater functional activity when converted into $\mathrm{IgG}^{[35]}$. Second, HRIG consists of polyclonal antibodies from human plasma with a number of epitopes of RABVG, and the function of each epitope is independent of the others. Antibodies can effectively neutralize free virus by macrophage phagocytosis or complement-mediated cytotoxicity. However, Fab091, a monoclonal antibody, can only bind to a single epitope, limiting its ability to remove the virus.

In future studies, the Fab091 and human IgG Fc fragments could be fused and expressed in eukaryotic cells. The reconstitution of Fab091 to IgG is a strategy that could be used for future passive immunotherapy against RABV infection ${ }^{[36-39]}$. Although Fab091 is different from scFv and IgG in biological function, tissue penetration, and half-life, the three together will not only retain the same binding specificity but also play complementary functional roles. They, together with other monoclonal antibodies, in accordance with the WHO-recommended "cocktail" therapy, can be used for post-exposure prophylaxis of rabies virus.

\section{Acknowledgements}

This investigation was supported by the National High Technology Research and Development Program, China (№ 2007AA02Z418). We would like to thank Chun-yan GU for valuable technical assistance and Johnson HUANG for revising the manuscript.

\section{Author contribution}

Chen LI carried out the molecular biology experiments and drafted the manuscript. Jin ZHU designed the study. Zhenqing FENG and Xiao-hong GUAN were involved in the design of the study, and Feng ZHANG, Hong LIN, Jin ZHU, Zhongcan WANG, Xin-jian LIU, Zhen-qing FENG, and Xiao-hong GUAN helped to draft the manuscript.

\section{References}

1 Komarova AV RE, Borman AM, Brocard M, England P, Tordo N, Hershey $\mathrm{JW}$, et al. Rabies virus matrix protein interplay with elF3, new insights into rabies virus pathogenesis. Nucleic Acids Res 2007; 35: 152232.

2 Margalith M VA. Sustained protective rabies neutralizing antibody titers after administration of cationic lipid-formulated pDNA vaccine. Genet Vaccines Ther 2006; 4: 2.

3 Irie T KA. Studies on the different conditions for rabies virus neutralization by monoclonal antibodies \#1-46-12 and \#7-1-9. J Gen Virol 2002; 83: 3045-53.

4 Bordignon J CF, Ferreira SC, Caporale GM, Lima Filho JH, Zanetti
CR. Calculating rabies virus neutralizing antibodies titres by flow cytometry. Rev Inst Med Trop Sao Paulo 2002; 44: 151-4.

5 Li C, Lin H, Liu XJ, Wang ZC, Zhou ZX, Chen LR, et al. Construction and screening of human immunized phage-display antibody libraries against rabies virus. Acta Univ Med Nanjing (Natural Sci) 2010; 30: 575-8.

6 Kovalskaya N HR. Expression and functional characterization of the plant antimicrobial snakin-1 and defensin recombinant proteins. Protein Expr Purif 2009; 63: 12-7.

7 Zhu J, Zhao P, Jiao YJ, Wang X, Cao BL, Feng ZQ, et al. Affinity Maturation and characterization of internalized human anti-Met recombinant antibody Fab. Prog Biochem Biophys 2007; 34: 73-9.

8 Barbas CF 3rd, Kang AS, Lerner RA, Benkovic SJ. Assembly of combinatorial antibody libraries on phage surfaces: the gene III site. Proc Natl Acad Sci USA 1991; 88: 7978-82.

9 Bellamy SR, Milsom SE, Kovacheva YS, Sessions RB, Halford SE. A switch in the mechanism of communication between the two DNAbinding sites in the Sfi I restriction endonuclease. J Mol Biol 2007; 373: 1169-83.

10 Corisdeo S WB. Functional expression and display of an antibody Fab fragment in Escherichia coli: study of vector designs and culture conditions. Protein Expr Purif 2004; 34: 270-9.

11 Sam brook J RD. Molecular Cloning: A Laboratory Manual. 3 ed. Cold Spring Harbor, New York: Cold Spring Harbor Laboratory Press; 2001.

12 Chatterjee DK ED. Enhanced soluble protein expression using two new fusion tags. Protein Expr Purif 2006, 46: 122-9.

13 Xiong L, Zhang AX, Li YQ, Zhang DW, Cao BL, Zhu J, et al. Reconstitution of human anti-Met genetic engineering antibody scFv. Acta Univ Med Nanjing (Natural Sci) 2009; 29: 605-17.

14 Zhao MP, Li YZ, Guo ZQ, Zhang XX, Chang WB. A new competitive enzyme-linked immunosorbent assay (ELISA) for determination of estrogenic bisphenols. Talant 2002; 57: 1205-10.

15 Tai HC, Campanile N, Ezzelarab M, Cooper DK, Phelps C. Measurement of anti-CD154 monoclonal antibody in primate sera by competitive inhibition ELISA. Xenotransplantation 2006; 13: 566-70.

16 Li WH MX, Qi ZT, Ni W, Zhu SY, Fang F. Proteomic analysis of differently expressed proteins in human hepatocellular carcinoma cell lines HepG2 with transfecting hepatitis B virus $X$ gene. Chin Med J (Engl) 2009; 122: 15-23.

17 Cliquet F AM, Sagné L. Development of a fluorescent antibody virus neutralisation test (FAVN test) for the quantitation of rabies-neutralising antibody. J Immunol Methods 1998; 212: 79-87.

18 Zhang SF, Cao L, Zhang F, Li HT, Li QZ, Zhang RL. Establishment and application of hybridomas producing anti-rabies nucleoprotein McAb and fluorescent antibody virus neutralization test. Chin J Lab Med 2006; 29: 554-7.

19 Goudsmit J MW, Weldon WC, Niezgoda M, Hanlon CA, Rice AB, Kruif $J$, et al. Comparison of an anti-rabies human monoclonal antibody combination with human polyclonal anti-rabies immuneglobulin. J Infect Dis 2006, 193: 796-801.

20 de Kruif J BA, Marissen WE, Kramer RA, Throsby M, Rupprecht CE, Goudsmit J. A human monoclonal antibody cocktail as a novel component of rabies postexposure prophylaxis. Annu Rev Med 2007; 58: 359-68.

21 Prosniak M FM, Hanlon CA, Rupprecht CE, Hooper DC, Dietzschold B. Development of a cocktail of recombinant-expressed human rabies virus-neutralizing monoclonal antibodies for postexposure prophylaxis of rabies. J Infect Dis 2003; 188: 53-6.

22 Bakker AB, Marissen WE, Kramer RA, Rice AB, Weldon WC, Niezgoda $M$, et al. Novel human monoclonal antibody combination effectively neutralizing natural rabies virus variants and individual in vitro escape 
mutants. J Virol 2005; 79: 9062-8.

23 Bakker AB, Python C, Kissling CJ, Pandya P, Marissen WE, Brink MF, et al. First administration to humans of a monoclonal antibody cocktail against rabies virus: safety, tolerability, and neutralizing activity. Vaccine 2008; 26: 5922-7.

24 Goudsmit J MW, Weldon WC, Niezgoda M, Hanlon CA, Rice AB, Kruif $\mathrm{J}$, et al. Comparison of an anti-rabies human monoclonal antibody combination with human polyclonal anti-rabies immuneglobulin. J Infect Dis 2006; 193: 796-801.

25 Satpathy DM, Sahu T, Behera TR. Equine rabies immunoglobulin: a study on its clinical safety. J Indian Med Assoc 2005; 103: 238, 241-2.

26 Ray K, Embleton MJ, Jailkhani BL, Bhan MK, Kumar R. Selection of single chain variable fragments $(\mathrm{scFv})$ against the glycoprotein antigen of the rabies virus from a human synthetic scFv phage display library and their fusion with the Fc region of human IgG1. Clin Exp Immunol 2001; 125: 94-101.

27 Henderikx P, Coolen-van Neer N, Jacobs A, van der Linden E, Arends JW, Müllberg J, et al. A human immunoglobulin G1 antibody originating from an in vitro-selected Fab phage antibody binds avidly to tumorassociated MUC1 and is efficiently internalized. Am J Pathol 2002; 160: 1597-608.

28 Beran J, Honegr K, Banzhoff A, Malerczyk C. Potency requirements of rabies vaccines administered intradermally using the Thai Red Cross regimen: investigation of the immunogenicity of serially diluted purified chick embryo cell rabies vaccine. Vaccine 2005; 23: 3902-7.

29 Kelly MP, Lee FT, Tahtis K, Power BE, Smyth FE, Brechbiel MW, et al. Tumor targeting by a multivalent single-chain Fv (scFv) anti-Lewis $Y$ antibody construct. Cancer Biother Radiopharm 2008; 23: 411-23.

30 Goncalvez AP, Chien CH, Tubthong K, Gorshkova I, Roll C, Donau O, et al. Humanized monoclonal antibodies derived from chimpanzee Fabs protect against Japanese encephalitis virus in vitro and in vivo. J Virol 2008; 82: 7009-21.

31 Mazor Y, Van Blarcom T, Iverson BL, Georgiou G. E-clonal antibodies: selection of full-length IgG antibodies using bacterial periplasmic display. Nat Protoc 2008; 3: 1766-77.

32 Mazor Y, Van Blarcom T, Mabry R, Iverson BL, Georgiou G. Isolation of engineered full-length antibodies from libraries expressed in Escherichia coli. Nat Biotechnol 2007; 25: 563-5.

33 Cardoso TC, Silva LH, Albas A, Ferreira HL, Perri SH. Rabies neutralizing antibody detection by indirect immunperoxidase serum neutralization assay performed on chicken embryo related cell line. Mem Inst Oswaldo Cruz 2004; 99: 531-4.

34 Houimel M, Dellagi K. Isolation and characterization of human neutralizing antibodies to rabies virus derived from a recombinant immune antibody library. J Virol Methods 2009; 161: 205-15.

35 Bender E, Woof JM, Atkin JD, Barker MD, Bebbington CR, Burton DR. Recombinant human antibodies: linkage of a Fab fragment from a combinatorial library to an Fc fragment for expression in mammalian cell culture. Hum Antibodies Hybridomas 1993; 4: 74-9.

36 Cheung SC, Dietzschold B, Koprowski H, Notkins AL, Rando RF. A recombinant human Fab expressed in Escherichia coli neutralizes rabies virus. J Virol 1992; 66: 6714-20.

37 Thullier P, Lafaye P, Megret F, Deubel V, Jouan A, Mazie JC. A recombinant Fab neutralizes dengue virus in vitro. J Biotechnol 1999; 69: 183-90.

38 Barbas CF 3rd, Crowe JE Jr, Cababa D, Jones TM, Zebedee SL, Murphy $\mathrm{BR}$, et al. Human monoclonal Fab fragments derived from a combinatorial library bind to respiratory syncytial virus $\mathrm{F}$ glycoprotein and neutralize infectivity. Proc Natl Acad Sci USA 1992; 89: 10164-8.

39 Lamarre A, Talbot PJ. Protection from lethal corona virus infection by immunoglobulin fragments. J Immunol 1995; 154: 3975-84. 